\title{
What Makes Qualitative Research Good Research? An Exploratory Analysis of Critical Elements
}

\author{
Felicity Agwu Kalu (Corresponding author) \\ School of Nursing, Midwifery \& Health Sciences, University College Dublin \\ Belfield, Dublin 4, Ireland \\ E-mail: Felicia.kalu@ucdconnect.ie; amakau2015@gmail.com
}

Jack C. Bwalya

School of Politics and International Relations, University College Dublin

Belfield, Dublin 4, Ireland

E-mail: jack.bwalya@ucdconnect.ie; jackcbwalya@gmail.com

Received: February 11, 2017 Accepted: March 24, 2017 Published: September 6, 2017

doi:10.5296/ijssr.v5i2.10711ＵRL: http://dx.doi.org/10.5296/ijssr.v5i2.10711

\begin{abstract}
When conducting research, it is essential that both the design and the method used are appropriate to fully answer the research questions. The overall aim of the study should determine the choice of the design. It is also crucial that the research is not only relevant but must be of good quality to provide knowledge that can be effectively used in various settings such as practice and education, as well as implementation of policies and projects. Qualitative research is used in various disciplines including behavioral and social sciences to understand human experiences and situations, as well as individuals' cultures, beliefs, and values. Qualitative research is very useful for exploring complex phenomena that are difficult to measure with quantitative studies. Despite the advantages of qualitative research, its trustworthiness is often questioned by some researchers and readers. This article presents an exploratory analysis of the essential elements in qualitative research that when properly and objectively utilised can enable the readers of qualitative work to judge it as a good research.
\end{abstract}

Keywords: Qualitative research, good research, research designs, research methodologies, research process, data trustworthiness. 


\section{Introduction}

Qualitative research is carried out to enhance understanding of individuals' cultures, beliefs and values, human experiences and situations, as well as to develop theories that describe these experiences (Creswell, \& Plano Clark, 2011; Munhall, 2012; Wuest, 2012; Holloway \& Galvin, 2016). This research approach emerged from the behavioral and social sciences as a method of understanding the unique, dynamic, and holistic nature of human beings (Hogan et al., 2009; Maxwell, \& Mittapalli, 2010; Creswell, 2014). Unlike a quantitative research approach that utilises numerical data to access information about the world, qualitative research does not transform verbal symbols into numerical data, rather the participants' and/or the researcher's words are used to describe the phenomenon being studied (Hogan et al., 2009; Sarantakos, 2013; Holloway \& Galvin, 2016). Qualitative research tries to get to the heart of what exactly happened to the participating individuals and what led them to decisions that they made and how the choices they made came to take the form that they eventually did (Curry et al., 2009; Yin, 2015). However, the trustworthiness of qualitative research is often questioned by some readers and quantitative researchers because the traditional concepts of validity and reliability are addressed differently between the two research approaches (Shenton, 2004; Ritchie, 2013). This article presents an exploratory analysis of the essential elements in qualitative research that when properly and objectively utilised can enable the readers of qualitative work to judge it as a good research. The article is structured as follows;

- Firstly, a brief cursory commentary of what makes qualitative research good research is outlined.

- Secondly, an in-depth consideration of some of the key elements within the qualitative disciplines including; research topic and research appropriateness, research question, theory, research design, methods of data collection and analysis, sampling, generalisation, and ethical consideration. These elements, if transparently utilised, can greatly improve the chances of the readers of qualitative work recognising a piece of qualitative research as good research.

- Thirdly, a conclusion of the article is given.

\section{Argument}

What makes qualitative research good research is the ability on the part of the researcher to systematically demonstrate transparency and accountability throughout the whole research process. This enables the readers of qualitative work to see the 'researcher's decision-making and the analytical approach...' (Holloway, 2005:6; Davies \& Hughes, 2014), that has been used from the start through to the end of the research. The orderly establishment of clarity and responsibility is made evident by constantly being reflexive in the decisions made regarding all the elements used in the research. Therefore, transparency, accountability and reflexivity should show through in the process of:

- Choosing the research topic

- Defining the research question

- Justifying the research appropriateness 
- Stating the adoption of the theory

- Outlining the research design,

- Choosing the sample and sampling strategy

- Methods of data collection

- Data analysis

- Applying consideration to research ethics.

- Demonstrating data trustworthiness

- Reflexivity

\subsection{Research Topic}

The selection of a research topic in qualitative research is heavily reliant on the researcher's views of his world. A clearly chosen qualitative topic should stem from everyday life, and needs to be relevant and interesting. For instance, the relevance of the research topic can be borne of current political debates in each area, thus when the topic is chosen, it will evoke some excitement (Guba \& Lincoln, 1989; Foster et al., 2015).

Once the research topic has been picked, then the researcher must be transparent about why the topic was chosen in the first place. Why it is an appropriate topic for the research, how relevant is the research in that given socio-cultural setting at that given point in history, and how -- if appropriate -- does the researcher envisage going about it. The researcher should also state clearly what other conceptual issues surrounding the research topic influenced his decision, taking into consideration things like the influence of his position in society. May (2011) asserts that researchers cannot be certain that what is appropriate for their culture will necessarily be appropriate for another, hence they need to be reflexive when making decisions about the research.

Therefore, a well-selected research topic to be investigated as well as clear details as to why it was chosen along with a detailed account of the researcher's reflexivity in the process, lays bare before the eyes of readers of qualitative work compelling reasons to consider the research as good qualitative research.

\subsection{Research Question}

After explicitly stating the theoretical stance based on their epistemological perspective with regard to the selection of the research topic, the researcher needs to clearly spell out a soundly constructed and designed research question/hypothesis. The clarity of the research question dictates exactly what other elements will be included in the research (Bryman, 2006; Merriam, \& Tisdell, 2015), for instance, what kind of methodological approach will be adopted for the research. Therefore, a well thought out research question is critical to not only deciding the specific type of research methods the research will embrace at the beginning of the research but as the research progresses as well (Maxwell, 1996; Flick, 2009; Punch, 2013).

Consequently, based on the researcher's epistemological and ontological perspective of their world, good qualitative research will have a well-developed and thought through research question. In qualitative inquiry initial questions for the research normally emerge from the 
researchers' real-life observations of the world (Marshall and Rossman 1995; Hatch, 2002; Punch, 2013). Thus, to achieve clarity with regard to the research question, the researcher will have to rationalise their choices for the chosen research question. One way of justifying to the reader the adoption of a research question is through an in-depth exploration of the literature on a topic that the researcher is interested in studying. This can help the researcher to pinpoint, based on the literature, where a gap lies in the body of research literature and thus a well formulated research question for their research can help them to fill that gap.

\subsection{Theory}

The use of theory is important in all research practices, but is more critical in qualitative research. It is widely acknowledged that having a prior theory aids the structuring of the whole research process (Creswell, 2003; Klenke, 2008). Though some within the qualitative discipline would argue otherwise, it is generally accepted that theory in qualitative research acts as an initial guide, for instance, to the adoption of the research design, which guides the data collection process as well as the kind of data collection techniques the researcher intends to use, in addition to the type of data he intends to collect and how that data will be analysed in the research (Eisenhardt, 1989; Ritchie et al., 2013).

The theoretical stance the researcher adopts when undertaking qualitative research is borne of their epistemological perspectives of their world. This stance thus influences and biases all the stages of the research process. However, in good qualitative research, this bias can be avoided when the researcher states clearly his own epistemological stance when undertaking the research. The research's readers are then helped to see from the researcher's point of view during the whole research process and in so doing lessen the bias associated with the research.

Even though it has been argued that any kind of research, be it quantitative or qualitative, undertaken in social sciences is value impregnated (Bhaskar,1989; Archer et al., 2013), sociologist Max Weber asserted that as social scientists we should strive to rid ourselves of values when undertaking research, as doing so would make our researches good research (Weber cited in Allen,2004:73). One way of ridding ourselves of value attachment is to explicitly state one's position with regards to the research you are undertaking (Finlay, 2006).

\subsection{Qualitative Research Design}

A well-articulated qualitative research spells out in very simple language, the research design that the research will embrace, coupled with the detailed rationalised method criterion the research will employ and how the data gathered will be analysed (Hatch, 2002, Seale, \& Silverman, 1997; Yin, 2016).

There are various designs to qualitative research. Examples of these designs are: phenomenology, ethnography, grounded theory, historical research, action research, and case study (Creswell, 2014; Holloway \& Wheeler, 2013; Yin, 2013). Grounded theory research is an inductive approach to research whereby data are collected and analysed, followed by development of theories that are grounded in the data (Creswell, 2014; Glaser \& Strauss 1967; Wuest, 2012;). Ethnographic studies seek to understand individuals' cultures, beliefs, and 
values in a natural environment of the people (Rolfe, 2013; Wolf, 2012; Spradley, 2016; Creswell \& Poth, 2017). Phenomenological studies explore the living experiences of individuals regarding a particular phenomenon and provides a greater understanding and awareness of the meaning such individuals attribute to their experiences (Creswell, 2014; Munhall, 2012; Rolfe, 2013). Historical studies involve systematic collection, evaluation, and synthesising of historic data to understand past events and then relating it to what is currently happening and what might happen in the future (Lundy, 2012; Rutherford, 2012). Historically data helps in building a body of a professional knowledge and roles (Creswell \& Plano Clark, 2011; Lundy 2012; Rutherford, 2012). Case studies are used for in-depth examination of individuals or groups of people (Hentz, 2012; Yin, 2013). Action research is employed to improve or refine practice, while noting the effects of the actions taken that resulted in an improved practice (Chenail et al., 2012; Holloway \& Wheelar, 2013; McNiff, 2013). The choice of any qualitative research design for a study should be dependent upon the purpose of the study and research questions in order to make it a good qualitative study.

\subsection{Sampling}

Sampling in qualitative research plays a vital role, as the essence of most qualitative researches is to study a phenomenon in its natural setting. It has been suggested that sampling in qualitative research helps the researcher to identify persons or localities rich in information and can be studied in much depth (Patton, 1990; Marshall \& Rossman, 2014).

Therefore, the reader needs to be provided with detailed information and explanation about why a particular sample was chosen and its appropriateness for the research, as well as what type of sample technique was employed. This is normally made evident by robust references from the literature detailing and rationalising about any sampling technique adopted by the researcher (Lincoln \& Guba, 1985; Patton, 2002; Cleary et al., 2014). For example, if a purposive sampling strategy was adopted for research, the reader of qualitative work will look for an in-depth rationalisation for choosing purposive sampling strategy as well as its appropriateness for the research.

\subsection{Data Collection Methods}

The freedom borne by qualitative research to choose a research framework most suitable for studying the social phenomenon, means that the researcher can choose to involve different methodological techniques such as interviews, documentary analysis, or focus groups in the study. This is true, for instance, when the researcher adopts a qualitative case study design. The availability of such different methodological techniques for exploring the phenomenon affords the researcher an opportunity to collect an abundant amount of information which would help to lessen bias, and enhance data credibility in the research (Mills and Huberman, 1994; Yin, 2003; Marshall \& Rossman, 2014). Eisenhardt (1989) contends further that the availability of multiple sources of data collection reduces bias in any given qualitative case study research thus giving well-balanced empirical results. Noble \& Smith, (2015) add that researchers can ensure bias is minimised in their research by evaluating the research process especially with regards to "...the rigour in which methods were undertaken and factors that may have biased findings” (ibid: 4). 
In the case of a qualitative case study design, it is then incumbent upon the researcher to explain clearly how, for instance, the methods used, whether interviews, documentary analysis or focus groups, complimented each other during the data collection and analysis processes (Drisko, 2005; Merriam, \& Tisdell, 2015).

The data collection stage is a crucial part of the qualitative research process, for it is during this period in the research that the researcher needs to reflect on the kind of methodologies adopted and the specific techniques used for collecting the data and their suitability to answering the research question, also the role that their presence as a researcher plays in the whole data collection process. Therefore, being aware of how their presence might impinge on the research and explicitly stating how this presence impacted the research process enhances transparency in qualitative research. The clarity of the whole data collection process, consequently enables the readers to make a judgment about whether the data collection methods used and the decisions made during data collection process were sensible (Holloway, 2005; Creswell, 2007).

\subsection{Data Analysis}

During this stage of the research process, it is again incumbent upon the researcher to be transparent, and to be able to provide ample information about the journey from data to conclusions. For example; the researcher should tell the reader how the data were analysed, the techniques of analysis used during the analysis process, the type of coding frames applied, even how many cases in the case of a case study design were examined, even was the data triangulated or not. It should also be stated clearly what, if any, relationship exists between the researcher and the data.

Silverman, $(1993,2016)$ concludes that the techniques chosen to describe how the process of analysing the data as well as how the conclusions are formulated may differ, but the researcher needs to provide sufficient clear information so that the reader can journey through the whole data analysis process and reach their own conclusions about how fair the process used in analysing the data was.

\subsection{Ethical Considerations}

Research can present risks to participants therefore the researcher has an obligation to ensure that their wellbeing is safeguarded throughout the research process (Polit \& Beck, 2010; Neuman, 2011; Munhall, 2012). Safeguarding participants’ wellbeing involves adhering to the standard ethical principles, which include respect for the autonomy of the participants, protecting participants from harm, confidentiality, informed consent and voluntary participation (Neuman, 2011; Scott, 2013).

It is best practice in any given research, but especially when dealing with real people, to respect the respondents' right to privacy. Miles and Huberman (1994) advise that we must consider the rightness or wrongness of our actions as qualitative researchers in relation to the people whose lives we are studying (1994:288; Creswell \& Miller, 2000).

In a good qualitative research study, the researcher accounts for transparency and 
accountability for the way the research was conducted by: openly stating how informed consent was sought from the research participants; demonstrating to the reader how the respondents' anonymity was preserved, informing the reader for instance, whether the participants' participation in the research was voluntary or not, and if liberty was theirs to withdraw from the research if they wished or chose to. Also by informing the reader whether the respondents were briefed about the research findings and did they have access to the eventual publication of the research, as well as a compelling and detailed analysis of all other ethical considerations. These reflections give an advantage, from the readers' perspective, for qualitative work to be judged good research. Further discussions on ethical considerations will be discussed under three ethical principles which include; (1) respect for person, (2) beneficence, and non-maleficence, and (3) justice.

\subsubsection{Respect for Persons}

The ethical principle of respect for human persons is concerned with the recognition of autonomy of the research participants. The principle of autonomy can be adhered to by providing adequate information about the research study to the participants in the participants' information leaflet, in an understanding manner to enhance their informed consent (Munhall, 2012; Scott, 2013).

\subsubsection{Beneficence and Non-Maleficence and Justice}

The ethical principles of beneficence (do good) and non-maleficence (do not harm) are concerned with the benefits and risks associated with conducting the research study (Sarantakos, 2013; Scott, 2013). It is also important to mention if there was a research study funded by any funding agency and if there was any pressure or conflict of interest from the agency that may have had adverse effect on sampling, collection, or analyzing of data to suit the agency. The ethical principle of justice is concerned with ensuring that procedures in the research study are fair and that the participants' rights to privacy are respected (Scott, 2013).

\subsection{Data Trustworthiness}

The trustworthiness of qualitative research is often questioned by the quantitative researchers and some readers because the traditional concepts of validity and reliability are addressed differently between the two research approaches (Shenton 2004; Marshall \& Rossman, 2014). There are many frameworks for ensuring rigor in qualitative research (Streubert, 1998; Shenton, 2004). Lincoln and Guba's (1985) framework, which is frequently cited for evaluating naturalistic work or other frameworks can used to guide the development of rigor in the qualitative aspects of a research study. Lincoln and Guba (1985) identified 4 criteria to judge the validity and reliability (more commonly referred to as trustworthiness) of the qualitative data produced. These include: credibility (internal validity), transferability (external validity/generalisation), dependability (reliability), and confirmability (objectivity) (Shenton 2004).

\subsubsection{Credibility}

Credibility refers to the accuracy of findings and how the researcher attempts to demonstrate 
that a true picture of the phenomenon being investigated is presented (Lincoln \& Guba's 1985). Credibility addresses the issue of whether consistency exists between the views of the participants and the researcher's representation of them (Ryan, Coughlan, Cronin, 2007). The credibility of the study can be achieved by using various methods such as interviews and focus group discussion, which are appropriate methods within the qualitative research and are well recognized research methods (Kreuger \& Casey 2009; Padgett, 2016).

Regarding preventing moderator bias during the data collection, the researcher must be aware of the possibility of a moderator bias in qualitative research interviews. Therefore, the researcher must try to remain objective (Timmins, 2006; Jootun 2009; McCabe \& Holmes 2009). This could be achieved by the researcher's effort to remain neutral as possible and by avoiding giving opinions while conducting interviews or focus groups (Timmins, 2006, Jootun, 2009). Interviews and focus group discussions should be tape recorded and transcribed verbatim to enhance accuracy of the data (Bryman, 2008, Goodman \& Evans, 2010, Krippendorf, 2013). Transcripts are compared with audio-recordings, to ensure accuracy of the data capture (Krippendorf, 2013). In addition, there should a clear and systematic description of the research path, including the research design, the collection of data, and the steps taken to manage, analyze and report data to further enhance the credibility of the study (Creswell, 2014). Credibility of the study can further be enhanced through reflexivity, and this can be achieved by the researcher describing and interpreting their own experiences as a researcher, in order to control bias (Koch, 2006; Le Gallais, 2008; McCabe \& Holmes, 2009). Reflexivity will be further discussed later.

\subsubsection{Transferability}

Transferability refers to how well the findings fit outside the study situation (Lincoln \& Guba, 1985; Marshall \& Rossman, 2014; Noble \& Smith, 2015). It has been argued that all good research needs to produce some ideas and results that can be applied generally. Unlike in the positivist traditions, generalisation in qualitative research is not aimed at making some grand statistical claims of research findings from a large randomised representative sample and applying them to a wider populace. Instead the concern is more on the richness and depth of the data and making sure that the findings can be transferable and have some relevance when applied to other contexts, situations, or individuals (Richie \& Lewis, 2003; Houghton et al., 2013). Therefore, generalisation can be achieved at different levels with the aim of attaining an in-depth understanding of a phenomenon under investigation. For example, through an analytical generalisation the researcher can test the validity of the outcomes of the research against the theoretical net that surrounds the phenomenon and the research questions (Yin, 1994, 2015).

Consequently, in good qualitative research, the researcher demonstrates the linkage between the data and the research conclusions, and this can be laid out before the reader's eyes. By explaining for example; as part of writing up the research findings, how a robust cross reference of the data and the conclusions took place, demonstrating to some extent that the researcher's results are valid. 


\subsubsection{Dependability}

Dependability refers to stability of the research findings and the researcher's attempt to account for any changing condition in the phenomenon of study, design, or methodology as appropriate (Lincoln \& Guba 1985; Houghton et al., 2013). It has been suggested that dependability is difficult to predict in a changing social world (Silverman, 2016). To ensure dependability, the researcher is expected to give the reader sufficient information needed to determine how dependable the study and researcher are (Ryan et al. 2007). For example, the use of qualitative content analysis for the focus group data analysis can facilitate the replication of results and making valid inferences from text to their contexts, with the aim of providing new insights, more understanding of a phenomenon, and informed practical actions (Krippendorf, 2013).

\subsubsection{Confirmability}

Confirmability refers to the steps taken by the researcher to demonstrate that findings emerge from the data and not their own predispositions (Shenton, 2004; Anney, 2014). Confirmability is achieved by ensuring credibility, transferability, and dependability (Ryan et al., 2007). To ensure confirmability of the study, a detailed account of the research processes should be provided. This will enable readers to determine whether the data analysis procedures were carried out appropriately (Streubert, 1998; Creswell, 2007).

In order to enable the readers of the research report to develop a thorough understanding of the chosen methods and their effectiveness, the research design and its implementation must be described. The evidence of a decision trail at each stage of the research process should be documented and produced. This is to provide the reader with evidence of the decisions and choices made regarding the theoretical and methodological issues throughout the study (Koch, 2006; Ryan, Coughlan, Cronin, 2007).

\subsection{Reflexivity}

Reflexivity is a concept of qualitative research rigor, which provides direction for researchers to be aware of bias and control by making an explicit quest to limit the researcher's effects on the data through self-awareness (Timmins, 2006, Jootun, 2009; McCabe \& Holmes, 2009; Flick, 2014; Holloway \& Galvin, 2016). Reflexivity involves raising of the researchers' awareness regarding how their presence affected the research process and the participants, as well as how the participants affected the researcher (McGhee, Marland, Atkinson, 2007; Le Gallais 2008; McCabe \& Holmes 2009; Holloway \& Galvin, 2016). Reflecting on the research process and understanding how the researcher's own values and views may influence findings can add credibility to the research as the researcher makes an effort to control bias (Jootun 2009).

\section{Conclusion}

Qualitative research promotes the understanding of human experiences and situations, individuals' cultures, beliefs, and values. It is particularly useful for exploring complex phenomena that are difficult to measure quantitatively. The choice of any qualitative research 
design for a study should be dependent upon the overall aim of the study to make it a good qualitative study. Despite the advantages of qualitative research, its trustworthiness is often questioned by some researchers and readers.

In this article, we have underscored that for any qualitative research to be judged as good research, there is a greater need for transparency, accountability, and reflexivity on the part of the researcher to explicitly account for all decisions made throughout the research process. Doing so enables readers of qualitative work to follow the researcher's decision-making processes, right from the outset of picking a research topic through to the research's conclusion.

At every stage the researcher must exhibit clarity and responsibility, as well as reflecting on the influence their presence as a researcher had on the research process. The stage for showing this may differ depending on the elements used in the research, but the principle remains the same, all good qualitative research must inform the readers of every single decision made at all stages of their research process.

\section{References}

Allen, K. (2004). Max Weber: A Critical Introduction. Pluto Press.

Anney, V. N. (2014). Ensuring the quality of the findings of qualitative research: Looking at trustworthiness criteria.

Archer, M., Lawson, T., \& Norrie, A. (2013). Critical realism: Essential readings. Routledge. Bhaskar, R. (1989). The possibility of Naturalism ( $2^{\text {nd }}$ ed.). Hemel Hampstead: Harvest.

Brouse, S. H. (1993). Interpreting Qualitative Data: Methods for Analysing Talk, Text and Interaction. London: Sage.

Bryman, A. (2006). Paradigm Peace and the Implications for Quality. International Journal of Social Research Methodology 9(2): 111-26

Bryman, A. (2008). Social Research Methods. ( ${ }^{\text {rd }}$ ed.). Oxford: Oxford University Press.

Chenail, R. J., George, S., Wulff, D. and Robin, C. (2012). Action research: The methodologies In Munhall, P. L. (Ed.), Nursing Research: A qualitative perspective (5 ${ }^{\text {th }}$ ed.). (p.455-467). Ontario: Jones and Bartlett Publications.

Cleary, M., Horsfall, J., \& Hayter, M. (2014). Data collection and sampling in qualitative research: does size matter? Journal of Advanced Nursing, 70(3), 473-475.

Creswell, J. W. (2014). Research Design: Qualitative, Quantitative and Mixed Methods Approaches (4th ed.). Los Angeles: Sage Publications.

Creswell, J. W. (2007). Qualitative inquiry \& research design: choosing among fiveapproaches. Thousand Oaks, CA: Sage Publications.

Creswell, J. W. (n.d.). Research design: qualitative, quantitative, and mixed method 
approaches (2nd ed.). SAGE Publications.

Creswell, J. W., \& Miller, D. L. (2000). Determining validity in qualitative inquiry. Theory into practice, 39(3), 124-130.

Creswell, J. W. \& Plano Clark, V. L (2011). Designing and Conducting Mixed Methods Research ( $2^{\text {nd }}$ ed.). Los Angeles: Sage Publications.

Creswell, J. W., \& Poth, C. N. (2017). Qualitative inquiry and research design: Choosing among five approaches. Sage publications.

Curry, L. A., Nembhard I. M. and Bradley E. H. (2009). Qualitative and mixed methods provide unique contributions to outcomes research. Circulation 119, 1442-1452.

Davies, M. B., \& Hughes, N. (2014). Doing a successful research project: Using qualitative or quantitative methods. Palgrave Macmillan.

Drisko, J. (2005). Writing up Qualitative Research: Families in Society: Journal of Contemporary Social Services 86 (4): 589-593.

Eisenhardt, K. M. (1989). Building Theories from Case Study Research. Academy of Management Review 14 (4): 532-50.

Flick, U. (2014). An introduction to qualitative research. Sage.

Flick, U. (2009). An Introduction to Qualitative Research (4 ${ }^{\text {th }}$ ed.). Sage Publication, Inc.

Finlay, L (2006). Mapping Methodology. In Finlay, L. and Ballinger, C (eds). Qualitative Research for Allied health Professionals: Challenging Choices. Chichester, East Sussex: John Wiley.

Foster, J. G., Rzhetsky, A., \& Evans, J. A. (2015). Tradition and innovation in scientists' research strategies. American Sociological Review, 80(5), 875-908.

Goodman, C. \& Evans, C. (2010). Focus groups In Gerrish, K. and Lacey, A. (Eds.), The Research Process in Nursing (6 ${ }^{\text {th }}$ edn.). (p.358-368). Oxford: Wiley Blackwell Publications.

Guba, E., G. \& Lincoln, V. S. (1989). Fourth Generalisation Evaluation. Newbury Park. CA: Sage.

Hatch, J. A. (2002). Doing Qualitative Research in Education Setting. State University NewYork Press.

Hentz, P. (2012). Case study: the method In Munhall, P. L. (Ed.), Nursing Research: A qualitative perspective ( $5^{\text {th }}$ edn.). (P.359-369). Ontario: Jones and Bartlett Publications.

Hogan, J., Dolan P. \& Donnelly P. (2009) Introduction. In (Hogan, J., Dolan P. \& Donnelly, P. (Eds) Approaches to Qualitative Research: Theory and its Practical Applications. A Guide for Dissertation Students (1 ${ }^{\text {st }}$ edn.). (p.1-18). Cork, Oak Tree Press.

Holloway, I. (2005). Qualitative Research in Health Care. Open University Press. 
Holloway, I., \& Galvin, K. (2016). Qualitative research in nursing and healthcare. John Wiley \& Sons.

Holloway, I., \& Wheelar, S. (2013). Qualitative Research in Nursing and Health Care. Wiley-Blackwell Publications.

Houghton, C., Casey, D., Shaw, D., \& Murphy, K. (2013). Rigour in qualitative case-study research. Nurse researcher, 20(4), 12-17.

Jootun, D. (2009). Reflexivity: promoting rigour in qualitative research. Nursing Standard, 23(23), 42-46.

Klenke, K. (2008). Qualitative Research in the Study of Leadership (1 $1^{\text {st }}$ ed.). Emerald Group Publishing Ltd.

Koch, T. (2006). Establishing rigour in qualitative research: the decision trial. Journal of Advanced Nursing, 53(1), 91-103.

Kreuger, R., A \& Casey, M. A. (2009). Focus Groups: A practical Guide for Applied Research (4th ed.). Thousand Oaks: Sage Publications Ltd.

Krippendorf, K. (2013). Content Analysis: An introduction to its methodology (3rd ed.). Thousand Oaks: Sage Publications Ltd.

Le Gallais, T. (2008) Where I go there I am: reflections on reflexivity and the research stance. Reflective Practice, 9(2), 145-155.

Lincoln, Y., S. \& Guba, E. G. (1985). Naturalistic Inquiry. Newbury Park, California: Sage Publications.

Lundy, K. S. (2012). Historical research In Munhall, P. L. (Ed.), Nursing Research: A qualitative perspective (5th ed.). (p.384-397). Ontario: Jones and Bartlett Publications.

Marshall, C., \& Rossman, G. B. (2014). Designing qualitative research. Sage publications.

Maxwell, J. A. (2005). Qualitative Research Design: An Interpretative Approach (2nd ed.). Sage Publications, Inc.

May, T. (2011). Social Research: Issues, Methods and Processes (4th ed.). Open University Press.

McCabe, J., L. \& Holmes, D. (2009) Reflexivity, critical qualitative research and emancipation: a Foucauldian perspective. Journal of Advanced Nursing, 65(7), 1518-1526.

McGhee, G., Marland, G. R., \& Atkinson, J. (2007). Grounded theory: literature review. Journal of Advanced Nursing, 60(3), 334-342.

McNiff, J. (2013). Action research: Principles and practice. Routledge.

Merriam, S. B., \& Tisdell, E. J. (2015). Qualitative research: A guide to design and implementation. John Wiley \& Sons. 
Miles, M., B. \& Huberman, A. M. (1994). Qualitative Data Analysis. Thousand Oaks, CA: Sage.

Munhall, P. L. (2012). A Phenomenological Method in Munhall, P. L. (Ed.), Nursing Research: A qualitative perspective (5th Ed., pp. 113-175). Ontario: Jones and Bartlett Publications.

Munhall, P. L. (2012) Ethical considerations in qualitative research In Munhall, P. L. (Ed.), Nursing Research: A qualitative perspective (5th Ed., pp.491-502). Ontario: Jones and Bartlett Publications.

Noble, H., \& Smith, J. (2015). Issues of validity and reliability in qualitative research. Evidence-Based Nursing, ebnurs-2015. Retrieved from http://eprints.hud.ac.uk/id/ eprint/22163 /1/EBNBiasFINALJuly2014.pdf

Padgett, D. K. (2016). Qualitative methods in social work research (Vol. 36). Sage Publications.

Patton, Q. M. (1990). Qualitative Evaluation and Research Methods (2 ${ }^{\text {nd }}$ ed.). Newbury Park, CA: Sage Publication, Inc.

Patton, Q. M. (2002). Qualitative Evaluation and Research Methods (3 ${ }^{\text {rd }}$ ed.). Newbury Park, CA: Sage Publication, Inc.

Polit, D. F., \& Beck, C. T. (2010). Essentials of Nursing Research: Appraising Evidence for Nursing Practice (7th ed.). Philadelphia: Lippincott Williams and Wilkins Company.

Punch, K. F. (2013). Introduction to social research: Quantitative and qualitative approaches. Sage.

Ritchie, J., Lewis, J., Nicholls, C. M., \& Ormston, R. (Eds.). (2013). Qualitative research practice: A guide for social science students and researchers. Sage.

Richie, J., \& Lewis, J. (2003). Qualitative Research Practice: A Guide for Social Science Students and Researchers. Sage Publication, Inc.

Rolfe, G. (2013). Philosophical basis for research. In Curtis E. A. \& Drennan J. (Eds.), Quantitative Health Research: Issues and Methods $1^{\text {st }}$ Edn., (p.11-28). Berkshire, England: Open University Press, McGraw- Hill Education.

Rossman, C., \& Marshall, G. B. (1995). Designing Qualitative Research (2 ${ }^{\text {nd }}$ ed.). Newbury Park, CA Sage

Rutherford, M. M. (2012). History exemplar: more than good kind angels: exploring the value of nursing service. In Munhall, P. L. (Ed.). Nursing Research: A qualitative perspective (5 ${ }^{\text {th }}$ ed.) (p.399-417). Ontario: Jones and Bartlett Publications.

Ryan, F., Coughlan, M. \& Cronin, P. (2007). Step-by-step guide to critiquing research. Part 2: qualitative research. British Journal of Nursing, 16(12), 738-744.

Sarantakos, S. (2013). Social Research. (4 $4^{\text {th }}$ edn.). Palgrave Macmillan Publications, London. 
Scott, P. A. (2013). Ethical Principles in Health Care Research. In Curtis E. A. \& Drennan J. (Eds.), Quantitative Health Research: Issues and Methods ( $1^{\text {st }}$ ed.). (p.77-90). Berkshire, England: Open University Press, McGraw- Hill Education.

Seale, C. \& Silverman, D. (1997). Ensuring rigour in Qualitative Research. European Journal of Public Health, 7(4): 379-384.

Shenton, A. K. (2004). Strategies for ensuring trustworthiness in qualitative research projects. Education for Information 22, 63-75.

Silverman, D. (2016). Qualitative research. Thousand Oaks, CA: Sage Publications.

Spradley, J. P. (2016). The ethnographic interview. Waveland Press.

Streubert, H. J. (1998). Evaluating the qualitative research report In LoBiondo-Wood, G. and

Haber, J. (Eds) Nursing ResearchMethods, Critical Appraisal and Utilisation (4 ${ }^{\text {th }}$ edn.). (445-465). St. Louis: Mosby.

Timmins, F. (2006). Critical practice in nursing care: analysis, action and reflexivity. Nursing Standard 20(39), 49-54.

Wolf, Z. R. (2012). Ethnography: the method In Munhall, P. L. (Ed.), Nursing Research: A qualitative perspective (5 ${ }^{\text {th }}$ Edn.). (p.285-335). Ontario: Jones and Bartlett Publications.

Wuest, J. (2012). Grounded theory: the method In Munhall, P. L. (Ed.). Nursing Research: A qualitative perspective ( $5^{\text {th }}$ Edn.). (p.225-256). Ontario: Jones and Bartlett Publications.

Yin, R. K. (1994). Case Study Research: Design and Methods ( $2^{\text {nd }}$ ed.). Thousand Oaks, CA: Sage Publications.

Yin, R. K. (2003). Case Study Research: Design and Methods (3 ${ }^{\text {rd }}$ ed.). Thousand Oaks, CA: Sage Publications.

Yin, R. K. (2013). Case Study Research: Design and Methods (5 ${ }^{\text {th }}$ ed.). Sage Publications, Los Angeles.

Yin, R. K. (2015). Qualitative research from start to finish. Guilford Publications.

\section{Copyright Disclaimer}

Copyright for this article is retained by the author(s), with first publication rights granted to the journal.

This is an open-access article distributed under the terms and conditions of the Creative Commons Attribution license (http://creativecommons.org/licenses/by/3.0/). 